\section{Letters to the}

\section{Editor}

The Editor welcomes submissions for possible publication in the Letters to the Editor section that consist of commentary on an article published in the Journal or other relevant issues. Authors should:

- Include no more than $\mathbf{5 0 0}$ words of text, three authors, and five references

- Type with double-spacing

- See http://jtcs.ctsnetjournals.org/ misc/ifora.shtml for detailed submission instructions.

- Submit the letter electronically via jtcvs.editorialmanager.com.

Letters commenting on an article published in the JTCVS will be considered if they are received within 6 weeks of the time the article was published. Authors of the article being commented on will be given an opportunity of offer a timely response ( 2 weeks) to the letter. Authors of letters will be notified that the letter has been received. Unpublished letters cannot be returned.

\section{Does the amount of fluid really matter for drain removal after lung resection?}

\section{To the Editor:}

We read with great interest the article entitled "Results of Prospective Algorithm to Remove Chest Tubes After Pulmonary Resection with High Output" by Cerfolio and Bryant. ${ }^{1}$ As the authors mentioned, drain-removal protocols vary considerably among thoracic surgeons: Some prefer the more conservative approach wherein the drain is kept in situ until the daily drainage is less than $150 \mathrm{~mL}$, whereas other researchers, including the authors, remove the drains more aggressively (when the amount of drain fluid is $450 \mathrm{~mL} / \mathrm{d}$ ) without encountering a complication. Drain removal is a subject of interest in recent years because early removal allows early hospital discharge. Therefore, determining the upper limit of the amount of drain fluid that would be safe is an important issue.

Thoracic surgeons traditionally emphasize the amount of fluid for drain removal. The fluid by itself does not cause complications in the chest cavity. The pleurae have a great capacity of fluid absorption that can reach up to $2 \mathrm{~L} / \mathrm{d}^{2}$ Drainage of intrapleural fluid with low protein content (drain protein/blood protein $<0.5$ ) is barely indicated. On the contrary, a high-protein fluid in the chest cavity needs to be removed to prevent several consequent complications. Drainage fluid invariably contains a high amount of protein because of bleeding after pulmonary resection. In this setting, the main function of a drain is not only to remove the fluid collected in the chest cavity but also to eliminate high proteins from the blood. In this regard, compared with the amount of drain fluid, the protein content of the drain fluid seems to be a better indicator for drain removal.

In our unpublished study, the pattern of protein content of drain fluid was investigated in 50 consecutive patients who had undergone straightforward lobectomy (Figure 1). During the study, drains were removed in accordance with the routine approach, and the results were analyzed at the completion of the study. This study showed that even when the drains were removed in only 4 patients $(8 \%)$, the ratio of drain protein to blood protein was less than 0.5 in all the patients on postoperative day $1(P<.00001)$. Relatively selected cases decrease the power of our study, but the findings suggest that the ratio of drain protein to blood protein $(<0.5)$ may be used as a more adequate indicator for early drain removal after lung resection. According to our recent policy, if air leak is not detected, we remove the drain(s) even on the

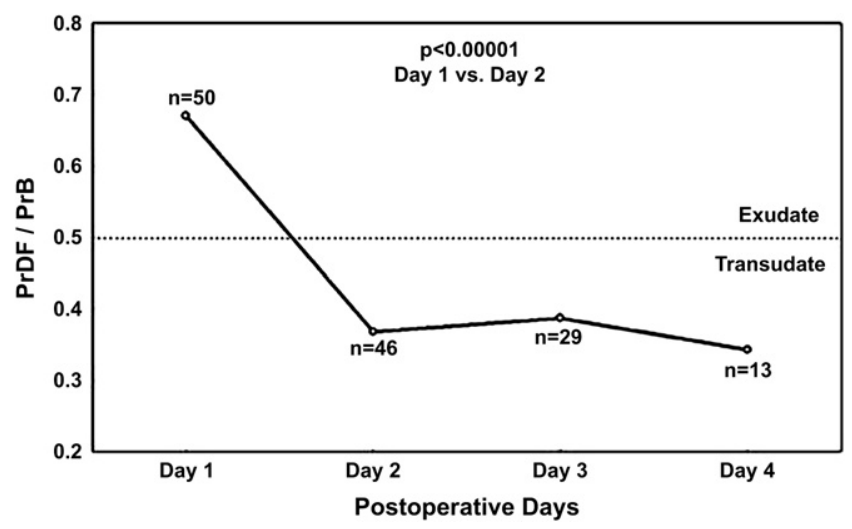

Figure 1. The ratio of drain protein to blood protein on postoperative days after lobectomy. Numbers indicate patients whose drains were kept in situ during the indicated postoperative days. PrDF/PrB, Ratio of drain protein to blood protein.

The Journal of Thoracic and Cardiovascular Surgery • Volume 136, Number 2535 
operation day or the next day depending on the protein content, regardless of the amount of daily drainage. This prospective and randomized study is currently in progress in our department. The preliminary data suggest that although the protein content and amount of drain fluid eventually correlate, the former decreases more rapidly than the latter. In this regard, we believe that surgeons can remove drains more aggressively even with daily drainage more than $450 \mathrm{~mL}$.

Atilla Ozdemir, $M D$

Aysun K. Misirlioglu, MD

Cemal A. Kutlu, MD, FETCS

Department of Thoracic Surgery

Sureyyapasa Chest Diseases and Chest Surgery

Teaching and Research Hospital

Istanbul, Turkey

\section{References}

1. Cerfolio RJ, Braynt SA. Results of prospective algorithm to remove chest tubes after pulmonary resection with high output. J Thorac Cardiovasc Surg. 2008;135:269-73.

2. Misserocchi G. Physiology and pathophysiology of pleural fluid turnover. J Eur Respir 1997;10:219-25.

doi:10.1016/j.jtcvs.2008.03.054

\section{Reply to the Editor:}

We appreciate Ozdemir and colleagues' letter concerning our article "Results of a Prospective Algorithm to Remove Chest Tubes After Pulmonary Resection with High Output." We are aware that some groups have evaluated the amount of protein in the pleural effluent to help guide the decision as to when it is safe to remove a tube. We believe this variable may be more important in the management of chest tubes in patients who present with a pleural effusion and not as important for those who have undergone elective pulmonary resection. Although chylothorax can occur after elective pulmonary resection, a clinically significant amount of chyle is usually easily detected once a patient is eating a regular diet because of the obvious milky nature of the effluent. However, as we described in our article, it may be safe to remove chest tubes after elective pulmonary resection even when the output is greater than $450 \mathrm{~mL} / \mathrm{d}$, and perhaps the protein content is a variable that should be tested along with a higher volume. We look forward to a peer-reviewed published article from Ozdemir and colleagues that critically and carefully tests this theory and the results.

\section{Robert James Cerfolio, MD, FACS, FCCP University of Alabama at Birmingham Cardiothoracic Surgery Birmingham, Ala doi:10.1016/j.jtcvs.2008.04.018}

\section{Prospective algorithm to remove chest tubes after pulmonary resection with high output - is it valid everywhere? \\ To the Editor:}

I consider the article published by Drs Cerfolio and Bryant ${ }^{1}$ an important contribution to the discussion regarding the amount of maximal daily pleural drainage allowed to remove a chest drain. The thoracic community widely accepts a range from 100 to 250 $\mathrm{mL} / \mathrm{d}$ as a safe amount; however, this is based on personal or historical experience rather than on published data. I appreciate the majority of theses and considerations presented by the authors but particularly the discussion clearly presenting the limitations to their study.

Encouraged by the presentation of their material in June 2007, I decided to change our common protocol based on acceptance of $200 \mathrm{~mL} / \mathrm{d}$ or less as a safe fluid amount for removal of the pleural drain (obviously not milky or bloody). This protocol was verified by thousands of our patients (we perform 600-800 open thoracotomies per year). Because our regional and single center covers the whole region of Western Pomerania in Poland, we are able to offer regular follow-up for the majority of our patients because they have no other option. We cooperate strictly with 5 large pulmonology units, so we usually quickly receive detailed information about our former patients. Our follow-up system seems more unified and strict than in Alabama, so I can confirm that readmissions because of effusions were incidental.

After changing our practice to the limits presented by the authors (drain removed if the amount of pleural drainage was $<450$ $\mathrm{mL} / \mathrm{d}$ ), we surgically treated 40 patients (20 lobectomies, 1 bilobectomy, 2 segmentectomies, and 17 wedge resections by open thoracotomy) who had pleural drainage of more than $450 \mathrm{~mL}$ on postoperative day (POD) 1 (some patients did not reach $450 \mathrm{~mL} / \mathrm{d}$ of pleural drainage and were excluded). The chest tube was removed on POD 1 in 15 pa- tients and on POD 2 in 25 patients; on POD 3 , all patients were discharged.

Six patients $(15 \%)$ were readmitted 4 to 10 days later with pleural effusion confirmed by ultrasonography. They were all treated by thoracentesis (repeated twice in 4 patients), and the average amount of fluid evacuated was $600 \mathrm{~mL}$ per thoracentesis. All patients were discharged 3 to 4 days later except 1 patient with pleural empyema who required drainage.

As a result of this experience, we abandoned the recommendations presented by Dr Cerfolio and coauthors and returned to our common rules (drain removal if the amount of fluid is $<200 \mathrm{~mL} / \mathrm{d}$ ).

We discussed the situation with our team and concluded that the pleural space is somewhat "mysterious" and that its status depends on many external conditions (eg, altitude above the sea level, air pressure, strong winds, adjacent lung conditions). Rules that are good in one location are difficult to accept in other location. Pleural surface inflammation described by the authors as a factor increasing absorption of the fluid can be easily presented in a reverse way; one of the common symptoms of "pleuritis" is the production of pleural fluid (except so-called pleuritis sicca). Disappearance of the pleural space fluid is an indicator of the healing process. Perhaps $450 \mathrm{~mL} / \mathrm{d}$ is a safe amount for chest drain removal in Birmingham but not in Szczecin or elsewhere. Nevertheless, I appreciate the efforts of Dr Cerfolio's team to elucidate the mysteries of this extremely interesting space.

Tomasz Grodzki, MD Regional Hospital for Lung Diseases Thoracic Surgery Szczecin, Poland

\section{Reference}

1. Cerfolio RJ, Bryant AS. Results of a prospective algorithm to remove chest tubes after pulmonary resection with high output. $J$ Thorac Cardiovasc Surg. 2008;135:269-73. doi:10.1016/j.jtcvs.2008.04.017

\section{Reply to the Editor:}

We appreciate Dr Grodzki's interest in our article. ${ }^{1}$ We are honored that he has applied some of the concepts we presented toward his practice. He has used, as per our recommendation, the removal of chest tubes when the output is $450 \mathrm{~mL} / \mathrm{d}$ or less, assuming it is not blood or chyle. However, it is 